\title{
Environmental Risk Factors Influencing Diarrheal Occurrence among Children Under Five Years Old in Informal Urban Settlements: A Case Study of Korogocho, in Nairobi County, Kenya
} Muriithi David Ikua (MA) ${ }^{1 *}$, Wakajummah John Obwa (MA) ${ }^{2}$, Kennedy Japhan Omoke (Ph.D.) $)^{2}$

${ }^{1}$ Ph.D. Student, University of Nairobi, Department of Geography and Environmental Studies, P.O. BOX 54-10204 Kiriaini, Kenya

${ }^{2}$ Senior Lecturer, University of Nairobi, Department of Geography and Environmental Studies, P.O. BOX 30197-00100 Nairobi, Kenya

*Corresponding author: Muriithi David Ikua (MA)

Abstract

The paper's main objective is to establish the relationship between environmental risk factors of childhood diarrhea and its occurrence in the Korogocho slum in Nairobi County. The hypotheses to be tested were; no significant relationship between environment and external risk factors and contraction of childhood diarrhea for those younger than five years in the Korogocho slum. The study variables included treatment of and sources drinking water, type of and cleanliness of toilet facilities, and accessibility. Self-reporting and two-week recall was the data collection strategy adopted for diarrhea outcome and its determinants. The selection of households for respondents (mothers of the target population) used systematic random sampling. Every third household with a child below five years of age was selected. When there was no child in the third household, the researcher went to the next one with a child's mother below five years until the study achieved a sample size of 90 respondents. Data was collected using well designed open-ended questionnaires, and analysis used descriptive and chi-square statistics. Findings showed that community and household environmental factors positively impacted diarrhea for the target population in the Korogocho slum. However, access to and sharing toilet facilities were not statistically significant in contracting diarrhea for the sample group. Based on two weeks recall, $36.4 \%$ of mothers reported that their children within the age limit had contracted diarrhea. Based on the results, the study identified several recommendations and suggested areas for further research. The key recommendations are to institutionalize deliberate interventions to provide slum dwellers with clean and quality drinking water and proper sanitation facilities to ensure the safe and effective fecal waste disposal.

Keywords: Diarrhea morbidity and occurrence, Infant mortality rate, Environmental risk factors, Informal urban settlement, Access to sanitation, Access to water, Diarrhea pathogens, Household.

Copyright @ 2021: This is an open-access article distributed under the terms of the Creative Commons Attribution license which permits unrestricted use, distribution, and reproduction in any medium for non-commercial use (NonCommercial, or CC-BY-NC) provided the original author and source are credited.

\section{INTRODUCTION}

Diarrhea is an infection symptom brought about by parasitic, viral, or bacterial organisms, and the principal means of spreading is through water contaminated with fecal matter [1]. Such contaminated water has a high probability of containing the infectious diarrhoeal pathogens. There is a potential to spread diarrheal diseases from person to person, which is significantly improved by poor personal hygiene. Various elements can cause childhood diarrhea, ranging from intestinal infection to an alteration in diet. The disease's causation is also subject to mediums, including unclean surroundings, contaminated food, and drinking water [2]. Frequent handwashing is an effective prevention strategy [3].
Diarrheal diseases are a global burden, and living conditions in and around homes contribute to their influence. Households that lack adequate means of wastage disposal are significant sources of most environmental pollutants. In urban centers, the determinants of ill health are housing conditions, water, and sanitation. Overcrowding of people, such as slums, exerts pressure on infrastructure, and social amenities [4]. Approximately half a billion people globally lack adequate sanitation. The fact contributes to fatalities above five million annually, with children deaths accounting for more than half [5]. In developed nations, more than $50 \%$ of their population endure low sanitation standards and polluted water. 
In the world health report, WHO [6] accounted for a minimum of four environmental health risks. The risks include outdoor pollution, unhygienic conditions, poor sanitation, and drinking water. Timaeus and Lush [7] identify childhood diarrhea as a critical risk emanating from environmental and household factors. Smith and Ezzati [8] also assessed various disease burdens as consequences of either household or community ecological risks.

The former include contaminated water, indoor pollution from solid-fuel, unhygienic living conditions, improper disposal of waste, and mosquito exposure. The latter covers water pollution, industrial waste, and urban outdoor pollution. Furthermore, the indigent population in urban areas endure various health problems, with no significant influence on the physical environment [8].

\section{Research objectives and hypothesis}

The general aim of this paper seeks to evaluate the relationship between environmental risk factors and the contracting diarrheal diseases for children below the age of five years in the Korogocho slum.

\section{Specific Objectives}

This study evaluated

1. The relationship between environmental risk factors including source and quality of drinking water, levels of sanitation, and diarrhea in children below five years in the Korogocho slum

2. Policy recommendations on strategies that may influence the reduction of childhood diarrhea in Korogocho slum.

\section{Research Questions}

This study addressed these questions:

1. What is the relationship between the source and treatment of drinking water and childhood diarrhea in Korogocho slum?

2. What is the relationship between sanitation and the occurrence of childhood diarrhea in the Korogocho slum?

\section{Hypotheses}

The following hypothesis was the formation of evaluating critical relationships:

Ho No significant relationship exists to correlate environmental risk factors and diarrhea for children sample in the Korogocho slum.

$\mathrm{H}_{1}$ Alternative

\section{Justification and scope}

The research questions' structure sought out the provision of an informed evaluation of risk factors that lead to diarrhea in children in Korogocho Slum in Nairobi, Kenya. The study provides essential data to all the sectors involved in health, national development, and policy setting and implementation. The research dwelt specifically on households that live in this slum area and have been affected directly by childhood diarrhea.

\section{Statement of the Problem}

The morbidity of the targeted group due to diarrhea disease is worse in Nairobi. The city has numerous informal settlements that exhibit poor hygiene and sanitation (31\%). Kenyatta National Hospital statistics show a daily rate of between 10 and 20 diarrhea cases for the children cluster (9). Out of those cases, three to five of them require admission since they are severe. The informal settlements in the city contribute to most of the issues. High prevalence of diarrheal pathogens results from poor household hygiene, contaminated water, and improper sewer disposal.

WHO [6] quantified risk factors out of data from prevalence, causation, and exposure of diarrheal diseases into two. The study also associates almost $16 \%$ of diarrhea globally as consequences of poor sanitation and contaminated water. Categorization of diarrhea's environmental causes may follow many channels, such as by referring to a medium that may transport hazards, as individual risk factors (agents), or according to the danger's nature. Lopez and Murray [10] characterize medium that carries hazards to include: water used for drinking, which gets contaminated by hazards that cause diarrhea contaminated by either household waste or improper disposal of fecal matter.

\section{LITERATURE REVIEW Global perspective}

Roy, A. et al. (11) relates the degradation of Vellore town's quality of life as consequential of wastage disposal by slum dwellers on street sides. The degradation consequentially increases the burden of diarrheal disease to the subject population. Additionally, the study reports unhygienic environmental dwelling conditions of slum dwellers of Calculate, India, evidenced by inferior building materials and overcrowding. The monsoon season makes water logging in the slums of Tamil, Nadu, and Calcutta critical. Improper drainage systems lead to the accumulation of rainwater in the houses of the impoverished population. The surface runoff has germs that may cause diarrhea infections to the children cluster

Sharma (12) also reports poor disposal in Jammu town, India, with high substandard housing conditions. The slum dwellers contribute to pollution by disposing of garbage and solid waste in the open. Sundari (13) reports defecation in Chennai's open fields by $79 \%$ of migrant households because of a lack of latrine facilities. The study also finds limited access to community toilets provided by the municipality to only $13 \%$. Moreover, the study account for slum dwellers 
totalling five million lacked access to toilets facilities in Mumbai and Jammu and opted for open defecation.

Gupta et al. [14] report poor environmental and living conditions for Chandigarh's suburban houses. The urban indigent population in slums with access to a sewer system account for $33.4 \%$, a stark difference of the $98 \%$ record for the urban population. The urban centers also had a significant population that was very conscious of health status, with $94 \%$ of such households treating water through boiling or filtration before consumption. However, it was not the same for rural and slum households since only $10.8 \%$ and $2 \%$ used these techniques. Cairncross and Valdmanis's [15] findings highlighted several countries in sub-Saharan Africa with high mortality rates from diarrhea in urban areas compared to rural areas. WHO [16] identifies diarrhea for children below five years as a significant cause of illness for the children cluster. The most affected include children and infants in low-income settings.

A research study found a correlation between sanitation with the level of wealth in Accra, Ghana. Low-income households typically used pit latrines, while wealthier houses had flush toilets [17]. The study also found a tendency to dispose of wastewater, garbage, and excrement in streams, open spaces, and surface drains. Boardi also found a significant urban indigent population with between $30 \%$ and $60 \%$ living either in squatter settlements or slums. The households are more prone to pathogens since their construction is on dumping sites, marshy ground, or floodplains. Such houses exist on the outskirts of city limits since the population cannot afford better land. Ballantyne and Oelofse [18] also record similar livelihoods in Mizamoyethu, South Africa.

\section{Kenyan Perspective}

In Kenya, diarrhea accounts for the thirdhighest fatalities rate for children below five years, following malaria and tuberculosis [19]. The pathogens lead to the deaths of almost 100 children daily [20]. The mortality rate from diarrhea for the slums is worse because of poor sanitation and hygiene. The country also identifies diarrheal diseases as a leading cause of infrequent childhood morbidity and mortality [21]; $31 \%$ of the child mortality rate is a consequence of diarrhea [6]. The Ministry of Public Health and Sanitation [22] acknowledged that 16 million (48\%) Kenyans find safe drinking water inaccessible.

In Kenya, overcrowded urban settlements pose high prevalence rates of diarrhea of about $31 \%$ among children below five years [23]. The population of these areas have low income and endure poor living conditions. The sources of water include open well, with significant contamination from pit latrines. People in such settlements opt to either defecate in public or dispose of waste by wrapping since toilet facilities either have long queues or are far [24]. It is highly unlikely for the children to use the costly, crowded, and distant toilets, and so they opt for open fields. Fecal matter is especially hazardous in contaminating food, water, and other surfaces where children play. Open sewers are also conventional in Kenyan major urban centers, especially in slums, and these contaminate drinking water either during pipe delivery or at the point of the source. Children encounter fecal material and other household wastes in the neighborhood environment, thus increasing the chances of being infected by diarrheal germs.

KWAHO [24] assessed the challenges facing informal settlements as environmental risk factors. KWAHO ascertained a seasonal relationship between diarrheal morbidity and drinking water source; i.e., rainy seasons observed high morbidity while the dry season had low records. The logic implies an increased likelihood of rain surface runoff mixing up with known sources of diarrheal pathogens, household waste, and fecal matter. The contaminated mixture water through open delivery pipes increased the risk to the children below five years. Proposed interventions to mitigate the threat include frequent handwashing with soap, improving sanitation standards, and ensuring safe drinking water.

The National Council for Population and Development report [25] estimates a lack of access to basic sanitation for 16.4 million in the country, with 4.8 million living in an informal urban settlement. The Kenya morbidity disease pattern also highlights that poor sanitation and waterborne are underlying causes of over $60 \%$. A joint Ministry of Water and Sanitation and the Ministry of Health rapid assessment [22] indicated the National coverage was $49 \%$. Health statistics in Kenya have shown the same trend in diarrhea prevalence of $23 \%$ in $1983,19 \%$ in $1990,16 \%$ in 1996 , and $13 \%$ in 2009 in informal urban settlements [20, 26].

Nairobi's city council is incapable of collecting all its garbage, and there are no allocated dumping sites for communities within. The two factors influence accumulated waste in informal settlements within the city [27]. The principal slums of interest were Kawangware, Korogocho, Viwandani, and Njiru. The same study reports accumulation and blockage of drains from the uncollected garbage. The areas also have several broken and open pipes, and such waste contaminates the water supply, which increases the risk of contracting diarrhea pathogens to children below five years.

Poor living conditions are the traits exhibited by the informal settlements of Nairobi. The requirements include poor drainage and garbage disposal tactics, inadequate toilet facilities, lack of clean treated water, and lack of affordable housing. The slum dwellers of Korogocho also lack such necessary 
facilities, including electricity, drinking water supply, sanitation, etc. Another study conducted by [21] on the impact of household and community-level environmental factors in urban and rural Kenya showed that lack of latrines and excreta disposal facility and absence of refuse disposal pit revealed associations with higher diarrhea rates in Kenya. Gachogu [28] also noted the same factors influenced high diarrhea morbidity in rural areas. Ikiara [29] found that water supply had no influential relationships with diarrhea morbidity, particularly for preschool-aged children. The assessment illustrates that usage and the quality patterns of water at home, as opposed to the cleanliness of water at the source, maybe a determinant of the impact on diarrhea morbidity.

However, the previous studies did have gaps in their assessment like Mutunga [30], who looked at Nairobi as a whole without considering the socioeconomic status and areas prone to high risks of environmental pollution like slums. My research fills that gap of segregating a slum only as an area of study. Despite similarities between the study by Kwaho [24] and current author analysis of variable and diarrhea incidence [31], differences exist. Such variations include the site, the period, and the study population. A comparison of the current study with K'Oyugi [21] reveals gaps in the previous research in variables such as overcrowding in places of residence, covering of cooked food for the infant. Gachogu [28] did not include in her assessment the behavioral pattern of the sample population, while the current study consists of the same through primary sources of data.

The gap from a study by Ikiara [29] was that he considered accessibility and cleanliness of domestic water as a factor only and excluded sanitation and convenience to toilet facilities. The current study tried to fill this gap by looking at various environmental factors that might have a significant relationship with childhood diarrhea. Research by Muthee [32] showed that water and sanitation conditions in the house and community exposed children to pathogens and pollutants. People defecate in the open, and restrooms are inadequate. Both factors compound the unhygienic behavior at community and household levels, thus creating a hazardous environment for the target sample. The current study found a significant association between accessibility to restrooms and diarrhea and found out that the provision of adequate toilets and latrines facilities in Korogocho could highly reduce the incidence of diarrhea.

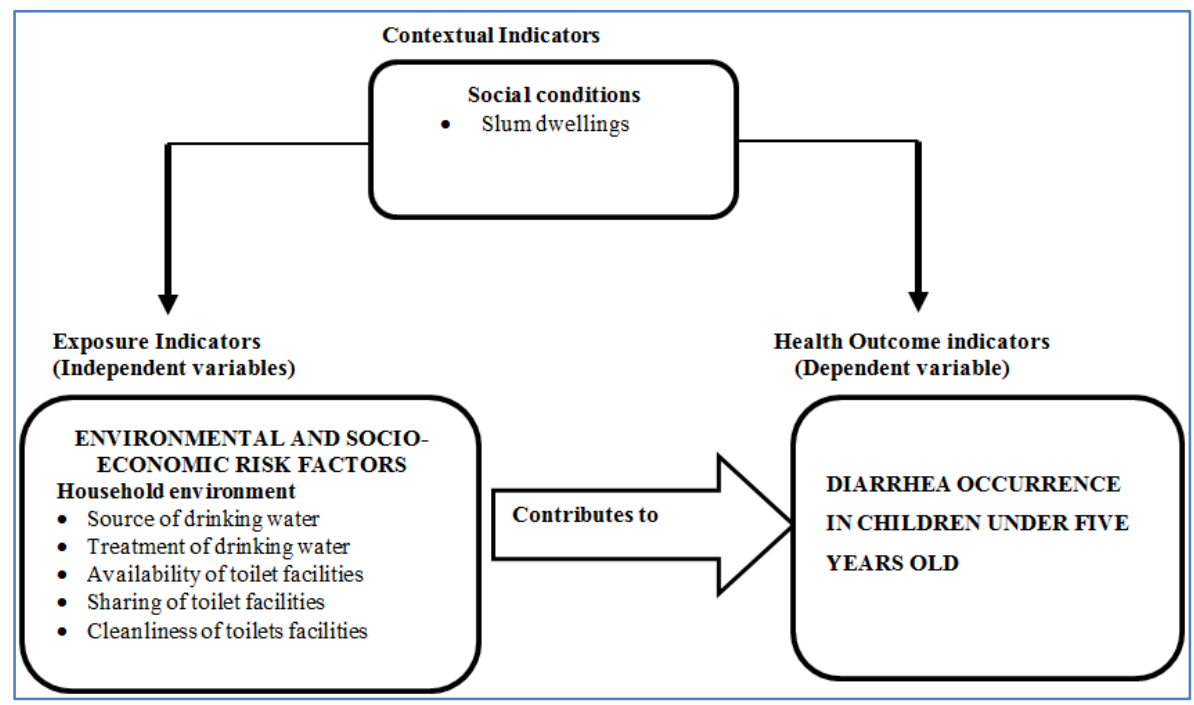

Fig-1: A Theoretical Model showing the conceptual framework of the study Conceptual Framework (Adopted from Briggs, D. (2)

\section{MATERIALS AND METHODS}

\section{Study area}

The capital city of Kenya - Nairobi - is unusually large within Eastern Africa and has a population that supersedes three million [13]. Estimations show the fastest pace of annual population growth in Nairobi within Africa, whereby the slums absorbs $75 \%$ of the highlighted populous [34]. The informal settlements in the city exhibit traits of insecurity, unsanitary, and highly dense living conditions. The slums only accumulate just $6 \%$ of the land in Nairobi, but houses about $50 \%$ of the city's population [34]. Nairobi has a current growth rate of $4.1 \%$, and estimations project the city's population at 5 million by 2025 [36]. 


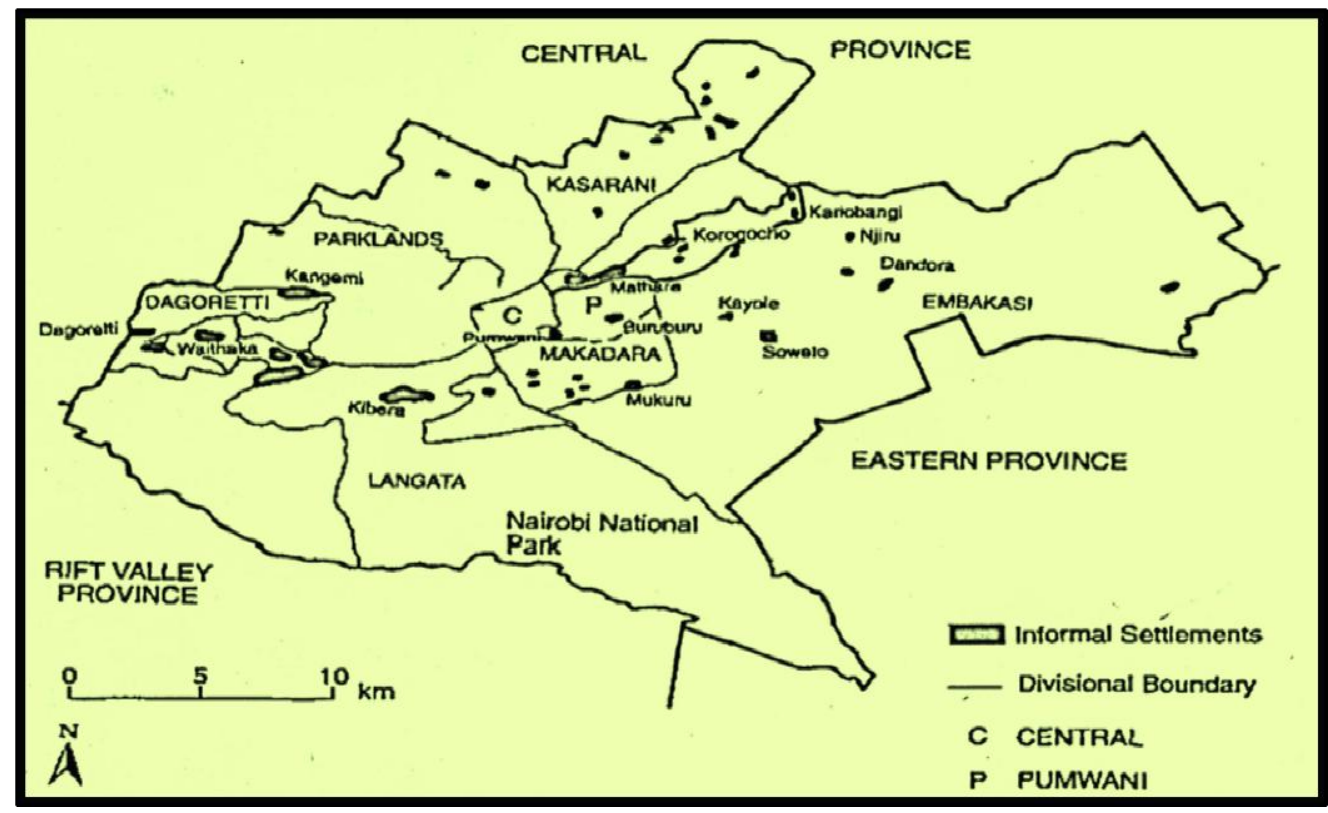

Fig-2: Map of the City of Nairobi showing Korogocho location - The study area Source: UNICEF [20]

\section{Korogocho slum}

Korogocho is located 11 Kilometres on the North-Eastern side of Nairobi city center with a population of 41,946 people and 12,909 households pressed in a 0.9 square kilometers area [37]. Korogocho comprises three sub-locations, namely; Nyayo, Korogocho, and Gitathuro. Each sub-location consists of villages, with those in Korogocho totaling to nine. Estimations from 2009 highlight Korogocho as the fourth largest slum in the city, following Kibera, Mathare, and Mukuru kwa Njenga. The study area houses residents from more than thirty ethnic groups, but the most prevalent include the Luhya, Luo, Kikuyu, and Somali ethnic groups. The majority of residents fit the category of low-income earners, exposed to poor living conditions and an environment characterized by inadequate and ineffective waste disposal and contaminated water supply, which are likely to increase diarrhea incidence among children below five years.

Only one tarmac grants access to Korogocho. However, various footpaths are usually congested and thoroughly polluted with household wastes, open sewerage, and drainage systems. There are little formal infrastructures for Korogocho residents. Most housing is by mud and recycled materials, built by families living there. In Nairobi, including Korogocho, informal settlement reported having a child mortality rate of $18 \%$ for children below five years, predominantly due to diarrhea and other preventable diseases. Improper means of disposing waste and lack of clean, accessible water pose a significant threat to livelihood in the area, particularly from waterborne diseases. Despite the availability of pay-toilets in the informal settlement, the cost implications are not affordable to the residents who opt for disposing of excreta in plastic bags. Korogocho also ha a broken sewer that disposes of waste from
Kariobangi estate into the slums, which further constricts the already narrow footpaths and contaminates tap water through defective pipes.

The Dandora dumping site - the largest dumping site in Nairobi - borders the Korogocho slums, which pose significant environmental and health risks for all surrounding settlements. Korogocho is home to a considerable population without access to health and social services. The construction of the houses in the area is from temporary and substandard materials. Mud is the building material for most walls, and roofing could incorporate polythene, carton papers, or sacks. The informal settlement has inadequacies in access routes, water provision, waste management, and lack of proper sanitation. Poor hygiene in this slum has resulted in the rapid spread of diarrhea and other waterborne diseases like cholera and typhoid. Korogocho slum endures inaccessibility to clean water and poor waste disposal. There is plodding progress towards improving the accessibility to safe drinking water and sanitation standards for the population.

The sanitation level in Korogocho is so bad that their open design drains the effluence after latrines fill up. The lack of water increases the risk since the waste only remains along the streets until the rainy season. During the rainy season, running streams carry the dry fecal matter to the nearby river through the open alley drains where children play and are exposed to fecal matter, increasing the chances of contaminating diarrhea pathogens. In Korogocho, the primary tactic of exhausting the few toilets available involves suing tins and emptying them into the river. Many people use these rivers in Korogocho to draw water for domestic use, mainly laundry purposes. The residents also have limited access to the restrooms since they are only open 
during the day, forcing residents to seek alternatives at night. The behavior increases community diseases, including cholera, dysentery, and typhoid in Korogocho, whose severe diarrhea symptoms. Children are particularly vulnerable to such conditions, which explains why cost implications for healthcare constitute a large percentage of expenditure for women in the area. In the early 1990s, WHO [6] highlighted food supply channels, contaminated water, and improper waste disposal as contributing to waterborne diseases in Korogocho. The research revealed that children below five years in slums were four times more likely to die than the rest of the population, and diarrhea was a leading cause of such fatalities. In Korogocho, it is easy for sewer waste and other pollutants to seep into water use in washing, cooking, and drinking. The context makes children below five years the most prone group to diarrheal infections and other infectious diseases.

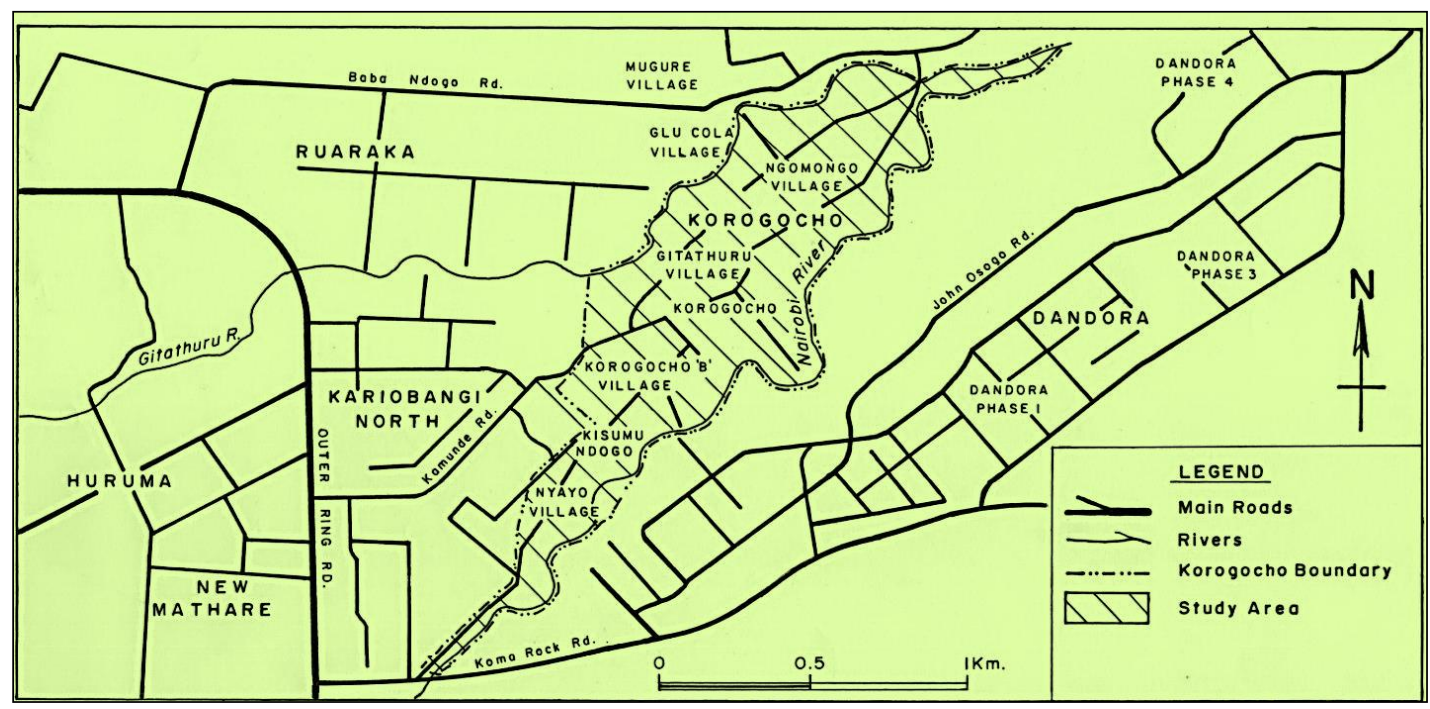

Fig-3: Map of Korogocho showing the study area Source: Author (31)

\section{METHODOLOGY}

The current study adopted a survey as the research design, which involved sampling three out of nine villages based on demographic and socio-cultural factors and randomly selecting the households in each pre-determined village to collect data from mothers of children aged five years and below. The design of questions asked in the questionnaires was from the research variables to elicit responses that could be analyzed to measure the study objectives and test the null hypothesis.

\section{Target population and sampling procedure}

The population of interest in this study was women with children aged five years or less in a household. The total number of homes in Korogocho was 12,909 , and the sample population was from the three sub-locations of Korogocho and one village in each sub-location. The residence with a woman having more than one child within the age limit accrued similar treatment with households that had only a single child within the cluster. However, the study accounted for diarrhea in each of the children. The sample size was 90 respondents proportionately distributed across the three sub-locations of the Korogocho location.

Korogocho slum was purposively sampled and selected from other slums like Kibera, Mathare, and Mukuru kwa Njenga within Nairobi County because the researcher had prior knowledge about the administrative and location of the tenement better than other slums within Nairobi. Korogocho being an enumeration area located in Ruaraka Constituency comprises three sublocations, namely; Nyayo, Korogocho, and Gitathuro. Each sub-location is further subdivided into villages totaling nine in the entire area. These villages are; Kisumu Ndogo, Korogocho, Korogocho B, Highridge, Gitathuro, Grogan A, Grogan B, and Ngomongo. Based on this distribution, three out of nine villages were selected based on social and cultural attributes like ethnicity and living (Kisumu Ndogo, Korogocho B, and Gitathuro).

The selection of respondents was through systematic random sampling. Every third household with a child below five years was selected. When there was no child in the third household, the researcher went to the next one with a child's mother below five years until it achieved a sample size of 90 . The study needed to make sure it was possible to use the results and findings in making accurate generalization at $95 \%$ confidence levels. The research used Fisher et al. [23] formulae of calculating the desired sample size, as shown below, based on the established $31 \%$ diarrhea prevalence among the children below five in Korogocho [23].

$$
n=z^{2} p q / d^{2} \quad \text { Where:- }
$$

$n=$ the desired population sample size (when the population is greater than 10,000) 
Muriithi David Ikua et al., Sch J Arts Humanit Soc Sci, Jan, 2021; 9(1): 19-30

$Z=$ the normal standard deviation (1.96) that corresponds to $95 \%$ confidence levels

$p=$ the Proportion of target population estimated to portray a particular characteristic $(31 \%$ of the population is children aged less than 5yrs with diarrhea infection).

Thus

$p=0.31, q=1.0-p=0.69$,

$d=$ degrees of accuracy desired (0.05)

The equation yielded a population sample size of 328 , with the estimated household size ratio to the total population of $1: 3.5(2 / 7)$; the household sample size was arrived at by multiplying the population size by the ratio of household the size to the total population as shown in the equation

$$
n=\frac{2}{7}\left(z^{2} p q / d^{2}\right)
$$

In this case, a sample size of households of $93 \pm 3$ was statistically significant to yield fairly accurate results. The sample size was distributed proportionately in the three sub-locations, as shown in the table. The number of housing proportionately distributed to the total sample size and the total number of households was the base for sample distribution in each sublocation.

Table-1: Population and sample size distribution table

\begin{tabular}{|l|l|l|l|l|c|c|}
\hline $\begin{array}{l}\text { Sub } \\
\text { Location }\end{array}$ & $\begin{array}{l}\text { Total Pop } \\
\text { (Census2009) }\end{array}$ & $\begin{array}{l}\text { No of } \\
\text { household }\end{array}$ & $\begin{array}{l}\text { No/Names of } \\
\text { villages }\end{array}$ & $\begin{array}{l}\text { Village } \\
\text { selected }\end{array}$ & $\begin{array}{l}\text { Selected no. of } \\
\text { households (n) }\end{array}$ & $\begin{array}{l}\text { Percentage of the } \\
\text { total sample size }\end{array}$ \\
\hline Nyayo & 9,638 & 3,300 & $\begin{array}{l}\text { Kisumu Ndogo } \\
\text { Nyayo } \\
\text { Highridge }\end{array}$ & $\begin{array}{l}\text { Kisumu } \\
\text { Ndogo }\end{array}$ & 23 & $25.6 \%$ \\
\hline Korogocho & 10,370 & 3,129 & $\begin{array}{l}\text { Korogocho B } \\
\text { Ngomongo } \\
\text { Grogan A }\end{array}$ & $\begin{array}{l}\text { Korogocho } \\
\text { B }\end{array}$ & 22 & $24.2 \%$ \\
\hline Gitathuro & 21,735 & 6,480 & $\begin{array}{l}\text { Gitathuro } \\
\text { Korogocho } \\
\text { Grogan B }\end{array}$ & Gitathuro & 45 & $50.2 \%$ \\
\hline Total & 41,743 & 12,909 & & & 90 & $100 \%$ \\
\hline
\end{tabular}

Source: Author (31)

\section{RESULTS}

\section{Diarrhea occurrence two weeks before the survey}

Based on two weeks recall, $35.6 \%$ of the child mothers reported that their children had suffered diarrhea-related illness two weeks before the study against $64.4 \%$ who claimed non-occurrence [31]. The response rate was $100 \%$

\section{Sources and treatment of drinking water in Korogocho}

The majority $(73.3 \%)$ of respondents in Korogocho reported that their primary drinking water source was from standpipes. Other water sources were water kiosks $(23.3 \%)$ and small water vendors (3.3\%). Concerning the treatment of drinking water to make it safe for drinking, the study found that not all households treated their water. However, most of the residents were aware there was a high probability of contamination of water from taps and other sources with germs. Most of the residents who never treated water $(41.1 \%)$ believed that water from standpipes, vendors, and tanks was chlorinated and safe for consumption.

\section{Availability and access to toilet facilities}

Access to toilet facilities was measured by asking the respondents whether there was an available toilet within a reasonable distance from the dwelling places. The study categorized responses into two; those that had access and those that did not have access. In
Korogocho, most of the respondents reported not to own a toilet $(83.3 \%)$, while a few reported owning a toilet $(16.7 \%)$. Most toilet facilities were composed of pit latrines, which were not well maintained and could overflow, especially during the rainy season (93.3\%). Only a small proportion of respondents reported having flush toilets inside their houses $(6.7 \%)$. The flush toilets also posed a significant challenge when water was not available in taps. $88.9 \%$ of the respondents reported to sharing of toilet facilities. The sharing of these essential facilities would make cleaning these facilities ineffective, which could likely increase the incidence of diarrhea in the target population. $36.7 \%$ of the respondents reported never cleaning that their toilet facilities regularly, while $63.3 \%$ said that the tenants and landlords regularly cleaned their toilets. The table below is a summary of this information. Although more than $85 \%$ of the respondents admitted to having access to a toilet facility, the findings indicate restrooms were inadequate and, at times, overflowing. The bettermaintained latrines were few and used at a fee. The study found out that residents faced maintenance challenges owing to the high number of people sharing them.

\section{Type of toilet facility}

The type of toilet affects the disposal of fecal matter. Flush toilets with adequate water are likely to reduce contamination of fecal matter with the surrounding environment. At the same time, there are 
expectations that a poorly constructed pit latrine would increase fecal contamination. The type of toilet facility used by the respondents categorized the sample as either Flush toilets or Pit latrine. The study did not account for other means of human waste disposal. 93.3\% of residents admitted to the usage of pit latrines. Most of these latrines were poorly constructed and could overflow when full and during the rainy season. Only $6.6 \%$ reported having access to flush toilets, which suffered from an inadequate water supply.

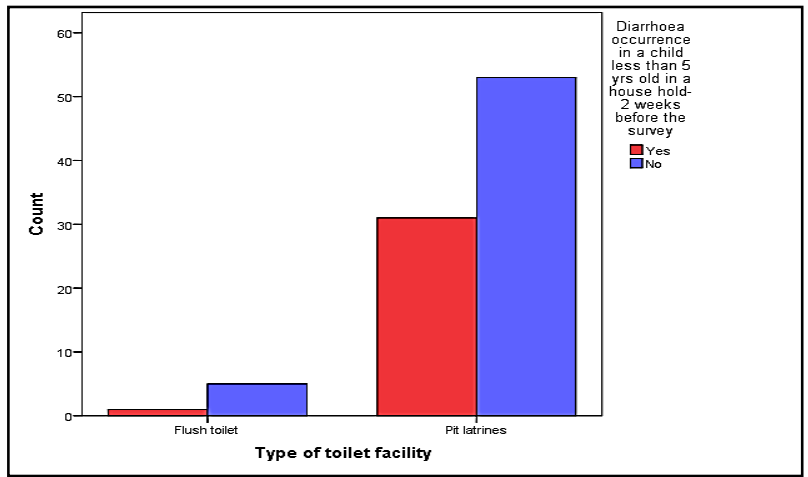

Fig-4: A comparative bar graph showing type of toilet facility in the study area

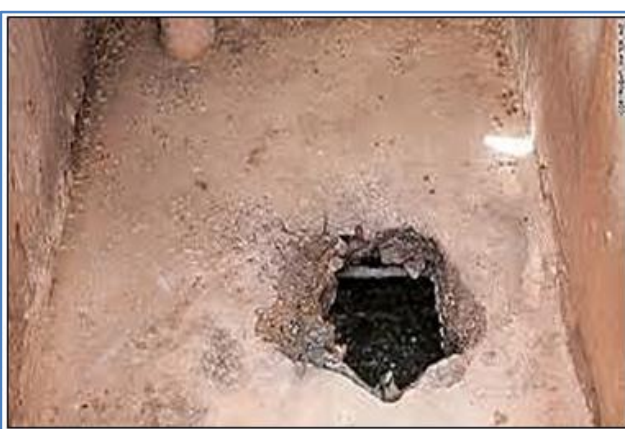

a) Pit latrine

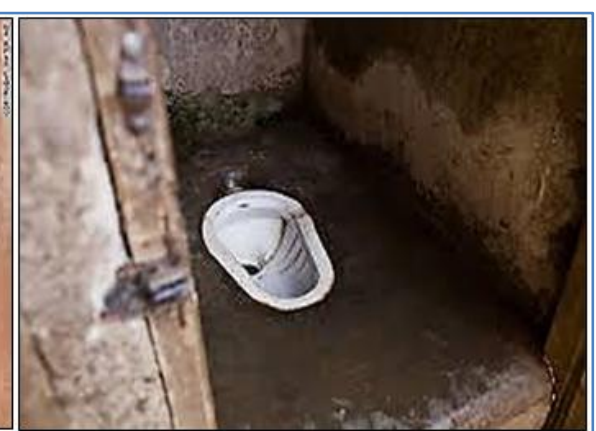

b) Toilet facility

Fig-5: A photograph showing type of toilet facility in the study area

Concerning latrine cleaning, most respondents $(61.1 \%)$ reported that their latrines were not regularly cleaned mainly for three reasons; cost implications for paying the cleaners, cost of water, and ignorance. Only $38.9 \%$ of respondents reported that their latrines were subject to regular cleaning or incurred dirt. The cleanliness of toilet facilities was measured by asking respondents whether their toilet facilities were regularly cleaned or not. Since all the cells had values more than five, the study adopted the chi-square test to analyze data. Data for these variables were put in a contingency table, as shown below.

Table-2: Cross tabulation table for descriptive statistics

\begin{tabular}{|c|c|c|c|c|}
\hline \multirow[t]{2}{*}{ Source of drinking water } & \multirow[t]{2}{*}{ Total count } & \multirow[t]{2}{*}{$\%$ count } & \multicolumn{2}{|c|}{$\begin{array}{l}\text { Diarrhea occurrence in children less than five years- } 2 \text { weeks before } \\
\text { the survey }\end{array}$} \\
\hline & & & Yes & ${ }^{2}$ \\
\hline Stand pipes & 66 & 73.3 & 27 & 39 \\
\hline Water Kiosks & 21 & 23.3 & 5 & 16 \\
\hline Vendors & 3 & 3.3 & 0 & 3 \\
\hline Totals & 90 & 100 & 32 & 58 \\
\hline \multirow[t]{2}{*}{ Treatment of drinking water } & \multirow[t]{2}{*}{ Total count } & \multirow[t]{2}{*}{$\%$ count } & \multicolumn{2}{|c|}{$\begin{array}{l}\text { Diarrhea occurrence in children younger than five years- } 2 \text { weeks before } \\
\text { the survey }\end{array}$} \\
\hline & & & Yes & No \\
\hline Yes & 53 & 58.9 & 11 & 42 \\
\hline No & 37 & 41.1 & 21 & 16 \\
\hline Totals & 90 & 90 & 32 & 58 \\
\hline \multirow[t]{2}{*}{ Access to a toilet facility } & \multirow[t]{2}{*}{ Total count } & \multirow[t]{2}{*}{$\%$ count } & \multicolumn{2}{|c|}{$\begin{array}{l}\text { The occurrence of diarrhea in children below five years- } 2 \text { weeks before } \\
\text { the survey }\end{array}$} \\
\hline & & & Yes & No \\
\hline Yes & 77 & 85.6 & 30 & 47 \\
\hline No & 13 & 14.4 & 2 & 11 \\
\hline Totals & 90 & 90 & 32 & 58 \\
\hline \multirow[t]{2}{*}{ Sharing of toilet facility } & \multirow[t]{2}{*}{ Total count } & \multirow[t]{2}{*}{$\%$ count } & \multicolumn{2}{|c|}{$\begin{array}{l}\text { The occurrence of diarrhea in children below five years- } 2 \text { weeks before } \\
\text { the survey }\end{array}$} \\
\hline & & & Yes & No \\
\hline Yes & 78 & 86.7 & 30 & 48 \\
\hline No & 12 & 13.3 & 2 & 10 \\
\hline Totals & 90 & 100 & 32 & 58 \\
\hline
\end{tabular}




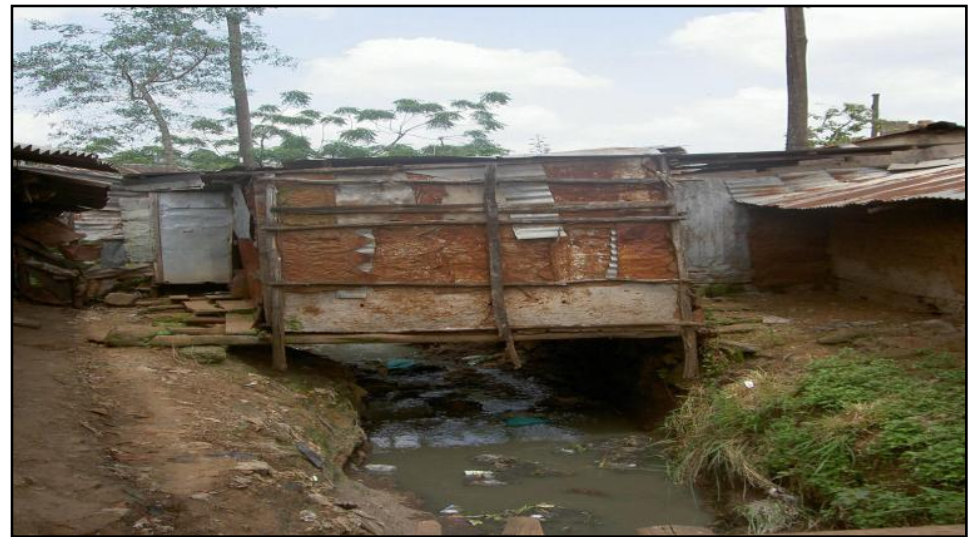

Fig-6: A photograph showing a pit latrine constructed across a river within the slum

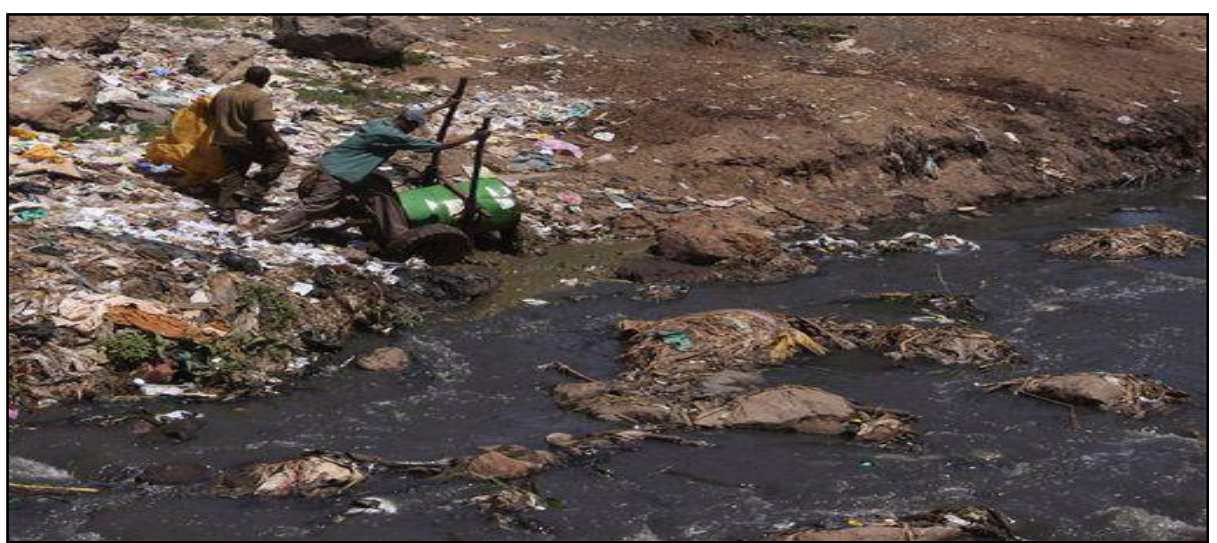

Fig-7: A photograph showing raw faecal matter being dumped across a river within the study area

\section{DISCUSSION}

The Chi-square test for the source of drinking water and diarrhea occurrence among children below five years $\left(\chi^{2}=3.745\right)$ did not show a significant relationship. This result could be interpreted that water could have been polluted mainly at the point of drawing, during transportation or storage. This test was not statistically significant at $(p>0.05)$, implying that the association's relationship was likely to have happened by chance. The null hypothesis was that there was no meaningful relationship between the source of drinking water and the diarrhea occurrence; therefore failed to be rejected. Regarding the treatment of drinking water to make it safe for drinking, the study found that not all households treated water for drinking even though most residents were aware that water from taps and other sources could have been contaminated with germs. Most of the residents who never treated water $(41.1 \%)$ believed that water from standpipes, vendors, and tanks was chlorinated and safe for consumption.
The Chi-square analysis between the treatment of drinking water and diarrhea occurrence in children below five years $\left\{\chi^{2}=12.325\right\}$ revealed that there was a significant relationship. This result means that the households that treated water were less likely to experience diarrhea incidences than those who did not treat water. The null hypothesis that there was no significant relationship between the treatment of drinking water and diarrhea disease in children below five years was rejected. This statistical test was significant at $p<0.05$, meaning that the association achieved was not likely to have been contributed by a chance of random sample.

The Chi-square analysis for regular cleaning of toilet facilities and diarrhea in children below five years $\left\{\chi^{2}=2.421\right\}$ revealed no significant relationship between them. This null hypothesis that there was no significant relationship between regular cleaning of toilet facilities and diarrhea among children below five years failed to be rejected. This test was not statistically significant at $p>0.05$, the likelihood that this relationship occurred by chance was high. 
Table-3: Contingency tables for the Chi-square tests

\begin{tabular}{|l|l|l|l|l|l|}
\hline \multicolumn{6}{|l|}{ Source of drinking water and Diarrhea occurrence in children younger than five years in a house hold-2 weeks } \\
before the survey -Cross tabulation for chi-square analysis
\end{tabular}

Treatment of drinking water and Diarrhea occurrence in children below five years in a household. Cross tabulation for the chi-square test

\begin{tabular}{|c|c|c|c|c|c|}
\hline \multirow{2}{*}{\multicolumn{2}{|c|}{ Treatment of drinking water }} & \multicolumn{3}{|c|}{$\begin{array}{l}\text { Diarrhea occurrence in children younger } \\
\text { than five years in a house hold- } 2 \text { weeks } \\
\text { before the survey }\end{array}$} & \multirow[t]{2}{*}{ Chi-square test results } \\
\hline & & Yes & No & Total & \\
\hline \multirow[t]{2}{*}{ Yes } & Observed Count & 11 & 42 & 53 & \multirow{6}{*}{$\begin{array}{l}\chi^{2}=12.325 \\
d=1 \\
p=0.05 \\
\text { Critical value }=(3.84)\end{array}$} \\
\hline & Expected Count & 18.8 & 34.2 & 53.0 & \\
\hline \multirow[t]{2}{*}{ No } & Observed Count & 21 & 16 & 37 & \\
\hline & Expected Count & 13.2 & 23.8 & 37.0 & \\
\hline \multirow[t]{2}{*}{ Total } & Observed Count & 32 & 58 & 90 & \\
\hline & Expected Count & 32.0 & 58.0 & 90.0 & \\
\hline \multicolumn{6}{|c|}{$\begin{array}{l}\text { Cleaning of toilet facility regularly and occurrence of diarrhea for children below five years in a house hold-Cross } \\
\text { tabulation for the chi-square test }\end{array}$} \\
\hline \multirow{2}{*}{\multicolumn{2}{|c|}{ Cleaning of toilet facility regularly }} & \multicolumn{3}{|c|}{$\begin{array}{l}\text { Diarrhea occurrence in children below five } \\
\text { years in a house hold- } 2 \text { weeks before the } \\
\text { survey }\end{array}$} & \multirow[t]{2}{*}{ Chi-square test results } \\
\hline & & Yes & No & Total & \\
\hline \multirow[t]{2}{*}{ Yes } & Observed Count & 9 & 26 & 35 & \multirow{6}{*}{$\begin{array}{l}\chi^{2}=2.421 \\
d=2 \\
p=0.05 \\
\text { Critical value }=(5.99)\end{array}$} \\
\hline & Expected Count & 12.4 & 22.6 & 35.0 & \\
\hline \multirow[t]{2}{*}{ No } & Observed Count & 23 & 32 & 55 & \\
\hline & Expected Count & 19.6 & 35.4 & 55.0 & \\
\hline \multirow[t]{2}{*}{ Total } & Observed Count & 32 & 58 & 90 & \\
\hline & Expected Count & 32.0 & 58.0 & 90.0 & \\
\hline
\end{tabular}

Source: Author (31)

\section{CONCLUSIONS}

Based on the discussion above, the findings can lead to several conclusions. One conclusion is that the principal risk factors for diarrhea in children younger than five do not encompass all environmental and household risk factors. One logic for the above statement is the lack of continuous contact between the risk factors and the target sample. The internal environment within a household provides a basis for evaluating the health levels in the place. Clean water, lack of hygiene, and proper sanitation are contributory factors that increase children's susceptibility to diarrhea infections.

The study also concluded that community environmental risk factors complemented the households' ecological risk factors in enhancing diarrhea incidence for the target sample. The presence of fecal deposits all over the houses' immediate environment in the study sample and the presence of a dumpsite nearby contribute towards the enhancement of diarrhea infections in children. The country lacks satisfactory standards in the highlighted facilities. Any improvement in the current sanitation conditions can yield a significant decrease in the incidence of diarrhea.

Another conclusion is that diarrheal infections in children below five years have a significant impact on these children's families. The incidence of diarrhea causes an increase in poverty as a result of the increased cost of medication. In Korogocho, the indicators for water and sanitation conditions in the home and community environment depicted shortage and exposed children to pathogens and pollutant risks. The lack of convenient and affordable water access has left residents to buy water from the vendors or walk long distances to public supply sources. 
The findings in this study lead to an overall conclusion that poor sanitation and inadequate water increase the prevalence of childhood diarrhea morbidity in the Korogocho slum. The outcome is also accompanied by inappropriate hygiene behaviors, overcrowding, and poverty, which predispose children to more risk of diarrhea. However, the interactions between multiple risk factors and diarrhea morbidity are complex within the home and environment context, beyond access to water and sanitation.

\section{RECOMMENDATIONS}

The conclusions above lead to the following recommendations

1. There is a need to institute deliberate interventions by Nairobi County Government to provide slum dwellers with clean water and sanitation facilities and ensure safe disposal of solid waste and fecal matter.

2. The environmental considerations need to be seriously adopted by the County and central Governments to ensure safer settlements free from pollution.

3. The provision of clean and quality drinking water should be a pre-requisite to the lives of people living in a poor urban environment by County and central Governments.

4. The Government and other stakeholders should ensure that the residents have clean and proper toilet facilities to minimize the risks of children contaminating diarrhea.

\section{Competing Interests}

interests exist.

Authors have declared that no competing

\section{Acknowledgments}

I thank the Almighty God for his abundant blessings and care in my life and giving me strength and good health in undertaking this academic study. I would wish to acknowledge and thank with sincerity the support of the following persons who, in many ways, contributed to the success of this project paper. My Supervisors; Dr. Margaret Kirimi, Mr. John Wakajummah, and Dr. Kennedy Japhan Omoke. All of the University of Nairobi for their guidance and outstanding mentorship throughout the study period.

\section{Authors' Contributions}

Author1 carried out this work under the guidance and supervision of authors ${ }^{2}$. Author ${ }^{1}$ conducted the study, executed the statistical analysis, and composed the draft of the manuscript.

\section{ABBREVIATIONS}

APHRC: African Population and Health Research Centre; MOPHS: Ministry of Public Health \& Sanitation; UNEP: United Nations Environmental Program; UNFPA: United Nations Population Fund;
UNICEF: United Nation Children Funds; WHO: World Health Organization

\section{Funding}

Funding for the research was part of the Master's Degree scholarship awarded by the University of Nairobi to the primary author between 1999 and 2014.

\section{Availability of data and materials}

The data used in this article is part of the primary data extracted from the author's Thesis submitted to the University of Nairobi for partial fulfilment of the requirement of the Degree of Master of Arts in Environmental Planning and Management in the Department of Geography and Environmental Studies.

\section{REFERENCES}

1. Larson CP, Lulseged S, Kitsela T. Childhood diarrhea. Epidemiology and ecology of health and disease in Ethiopia. 2006:339-49.

2. Briggs D. Introduction and Classification of childhood Diarrhea: Indicators to improve children's environmental health. The United Kingdom: WHO; 2008.

3. Ahmed, S. Burden and etymology of diarrhea disease in infants and young children in developing countries; a prospective case-control study. Lancet, Elsevier ltd; 1992.

4. Maria CN. Characterization and factors associated with diarrheal diseases [Published by Muhammad Asaduzzaman.]. Pan Afr Med J. 2013; 16:37.

5. United Nations. Road map towards the implementation of the United Nations Millennium Declaration. World Bank; 2001.

6. World Health Organization. Prevention of diarrhea (unit 8) - Medical Education: Teaching Medical Students about diarrhea diseases; 2005.

7. Teklemariam S, Getaneh $\mathrm{T}$, Bekele $\mathrm{F}$. Environmental determinants of diarrhea morbidity in under-five children. Keffa-Sheka Zone. Southwest Ethiopia; 2003.

8. Smith KR, Ezatti M. The impact of the environment on health by country: Water, Sanitation and Hygiene for the prevention of diarrhea, Geneva, Berkshire, and Kyoto, WHO; 2005.

9. Kariuki P. N. Risk Factors and Management of Infectious Diarrhea in Children at Kenyatta National Hospital, unpublished MSC thesis of UoN; 2010.

10. Murray C, Lopez A. Global Mortality and the contribution of risk factors: Global burden of disease study. London, World Bank; 1994, 1996a, $1997 \mathrm{a} \& 1998$.

11. Roy A. Slum free cities of the Asian century: postcolonial Government and the project of inclusive growth. John Willy \& Sons; 2011. 
12. Sharma K. Rediscovering Dharavi: Stories of Asia's largest slum. Penguin Books Australia; 2009.

13. Sundari S. Slum condition in Mumbai, ENVIS center, volume 5, No. 1 March 2008. Published by East Asian Forum. 2008; 37(2).

14. Gupta A. Rural migrants and urban segmentation: micro-level evidence from Delhi Slums, Economic and Political Weekly. 37(2); 2007.

15. Cairncross S, Valdmanis V. Evaluating for village water supply planning. New York: Oxford University Press; 2006.

16. WHO. Joint Monitoring Programme for water supply and sanitation. JMP report. 2014;8 (2): 1021, UNICEF; 2014.

17. Boardi KO, Kuitanen M, Raheem K, Hanninen K. Urbanization without development: environment and health implication in African cities. Environ Dev Sustain. 2005; 7(4):465-500. https://doi.org/10.1007/s10668-004-5410-3.

18. Ballantyne R, Oelofse C, Winter K; Ballantyne and Oelofse. Geography educators perception of teaching environmental education in South African schools. S Afr Geogr J. 1999;81(2):86-90.

19. Ziraba T. Maternal mortality in the informal settlements of Nairobi city. APHRC: 2012.

20. UNICEF. Ending preventable child deaths from pneumonia and diarrhea by 2025; the Integrated Global Action Plan for the prevention and control of Pneumonia and Diarrhea (GAPPD). United Nations; 2013.

21. K'oyugi BO. Determinants of Diarrhea and its treatment in Kenya. Nairobi, Population and studies research institute, UoN: 2004.

22. MOPHS. Intestinal parasitic infections in children presenting with diarrhea in outpatient and inpatient settings in an informal settlement of Nairobi. Kenya: Government press; 2010.

23. African Population and Health Research Centre. Population and health dynamics in Nairobi's informal settlement. Nairobi: African Population and Research center (APHRC); (1st ed. 2002), (2nd ed. 2006), (3rd ed. 2012).

24. KWAHO. A case study of Kibera Water and Environmental Sanitation Programme. Nairobi, African studies center, and UoN; 2008.
25. National Council of Population and Development NCPD. Session paper No. 3 of 2011. Nairobi, Kenya: Kenya Bureau of Statistics; 2011.

26. Juma, C. Disease and Mortality in Sub-Saharan Africa: 2nd edition, Harvard University; 2004

27. Amayunzu M, Taffa N. Child morbidity and health care utilization in the slum in the slum of Nairobi, APHRC, Oxford University Press; 2004.

28. Gachogu Peninnah Wanjiku. Determinants of Diarrhea and its treatment in Kenya. Unpublished MA Project, UoN; 2008.

29. Ikiara JK. A study of environmental factors and how they relate to the health of pre-school age children-A case study of Kibera slum. Nairobi, Unpublished MA thesis of UoN; 2002.

30. Mutunga C. Environmental, Determinants of Child Mortality in Urban Kenya. Nairobi: World Institute for Development Economic Research; 2004.

31. Muriithi DI. Risk factors influencing diarrhoea occurrence among children under five years old in informal urban settlements: a case study of Korogocho. Nairobi county. Kenya: University of Nairobi; 2014.[ [cited 2017 Oct 10], Available http://erepository.uonbi.ac.ke/handle/11295/76012? show $=$ full.

32. Veronica M. An investigation of water and sanitation risk factors associated with childhood diarrhea morbidity in Kibera. Nairobi: Boca Raton Lewis Publisher; 2009.

33. UNEP, Year Book 2013: Economic development and the expanding world. Nairobi, Publishing service by UNO; 2013.

34. Graham Alder. Tackling poverty in Nairobi's informal settlements; developing an institutional strategy. African studies center; 2013.

35. World Bank. Kenya Economic Update: Population, Water, Sanitation, and Hygiene at a glance, June 2011. World Bank; 2011.

36. WHO Huttley S. Morris, s and Pisani, v. Prevention of diarrhea in young children in developing countries, bulletin of the world health organization. 2013;75(2:163-174).

37. Report C. A survey of mother's knowledge about childhood diarrhea in Kenya. Nairobi: Government Press; 2009. 